\title{
Features of research of iron ore thermal decarbonization kinetics during roasting
}

\author{
M. I. Dli, Dr. Eng., Prof. ${ }^{1}$, e-mail: midli@mail.ru \\ V. I. Bobkov, Dr. Eng., Associate Prof. ${ }^{1}$, e-mail: vovabobkoff@mail.ru \\ N. S. Kulyasov, Cand. Econ., Leading Researcher of the Higher School of Tariff Regulation², \\ e-mail:nkulyasov@gmail.com \\ A. M. Sokolov, Leading Engineerl, e-mail:ansokol98@mail.ru
}

\begin{abstract}
${ }^{1}$ National Research University "Moscow Power Engineering Institute” - Smolensk Branch, Smolensk, Russia ${ }^{2}$ Plekhanov Russian University of Economics, Moscow, Russia
\end{abstract}

\begin{abstract}
The work is devoted to research of chemical-metallurgical decarbonization process in iron ore pellets, taking into account thermal and technological operation features of roasting conveyor-type machines. Calcination of pelletized iron ore raw material was experimentally examined, using the samples that save their initial structure within the temperature and heating rate ranges of the existing roasting conveyor-type machines. Appearance of essential temperature gradients in the examined samples was proved experimentally; it was connected with non-stationary heating conditions and thermal effects of carbonates dissociation reaction. These conditions and effects restrict possibility of use of the existing non-isothermal kinetic methods for determination of kind and parameters of kinetic equations. The relationship among heterogeneous endothermic transformations and thermal physical calcination conditions was revealed.
\end{abstract}

Key words: heterogeneous reaction, iron ore pellets, roasting, sintering, carbonates dissociation, temperature, material structure, calcination.

DOI: $10.17580 /$ cisisr.2021.02.01

\section{Introduction}

Prediction of availability of iron ore raw material for heat treatment, selection of power- and resource-efficient technological routes, operating procedures and their adaptation to periodically varying properties of iron ore raw material meet the lack of calculation techniques for thermal preparation and processing operations that rather completely take into account special features of this material. The data on thermal decarbonization kinetics, strictly required for quantitative calculations of chemical-metallurgical processes in the industrial roasting machines and ore smelting furnaces, are insufficiently substantiated and contradictory. Iron-bearing ores and minerals have complicated and heterogeneous polymineral composition. Source minerals, being subjected to heating, are characterized by physical-chemical transformations and mutual reactions; it leads to variations in composition and structure of materials, to appearance of heating effects and finalizes in accompanying by deep variations of thermal-physical parameters (TPP), such as heat capacity, temperature conductivity and heat conductivity. As soon as thermally activated chemical-metallurgical processes are determined by kinetic regularities and depend on heating conditions, TPP of iron ore raw material acquire complicated, temperature-temporal or temperature-concentrating type of relationships.

Especial methodical difficulties are arising also during examination of calcination kinetics of bulk and pelletized iron ore raw material, because the results of investigations are influenced by the heat exchange processes in the samples.
Lack of information about decarbonization kinetics of iron ore raw material as well as about the effect of chemical and mineralogical composition, material structure and heating rate on calcination process don't allow to use the existing literature data on the results of thermal analytical researches of separate types of iron ore raw material and "clean" carbonate materials for description of calcination process of iron ore raw material [1-3]. Thereby, experimental investigation of the processes of carbonates dissociation with use of samples saving their initial material structure within the temperature range close to practical range is required for establishing the general regularities of calcination chemicalmetallurgical process $[4,5]$. It can be found out e.g. in the area of high-temperature roasting of iron ore pellets in roasting conveyor-type machine or in sintered layer on the belt of a sintering machine $[6,7]$.

The first condition provides restriction on the minimal dimensions and shape of samples. Dimensions of samples should exceed substantially grain size of source minerals of typical dimension of structure of the examined material during all experiments $[8,9]$. Shape of a sample should be chosen based on minimization of distorting influence of mechanical activation of surfacial inclusions, i.e. the relationship "sample surface / sample volume" should be minimal wherever possible $[10,11]$.

The second condition can be realized during conduction of experiments with high heating rates. The conducted analysis of exploration of the industrial roasting machines, operating at metallurgical and mining-concentrating works at present tine, displays that heating rate of material grains varies in real conditions in wide range and can reach 2000-2500 K$\cdot$ hour $^{-1}$. 


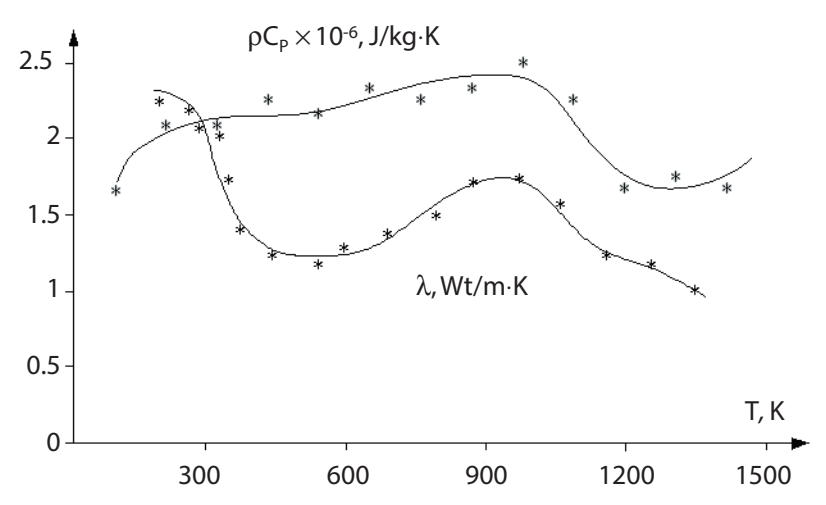

Fig. 1. Relationship among specific heat capacity and heat conductivity ratio for pellets (from one side) and temperature (from other side)

Simultaneous execution of the a.m. conditions can lead to appearance of substantial temperature gradients in the examined samples, connected with non-stationary heating conditions and heat effects of carbonated dissociation reactions [12, 13]. It will restrict possibility of using the existing methods of non-isothermal kinetics for determination of kind and parameters of kinetic equations [14, 15].

\section{Aim of the research}

This research is devoted (firstly) to estimation of thermalphysical conditions accompanying to heterogeneous endothermic processes in the examined iron ore materials and (secondly) to determination of possibility to use the existing methods for correct analysis of these processes.

\section{Simulation of thermal decarbonization of iron ore pellets}

When choosing the mathematical model describing decarbonization process, the following factors seem to be important:

- non-stationary temperature conditions accompanying to the processes;

- depending of thermal-physical material parameters both on temperature and transformation degree of reacting components.

The following admissions and suggestions were made at the same time:

- diffusion of gaseous product occurs easily and has no effect on the reaction rate;

- temperature relationship of the reaction rate is characterized by Arrenius features;

- specific heats of chemical transformations don't depend on the temperature.

Endothermic reactions of carbonates dissociation: $\mathrm{MgCO}_{3} \rightarrow \mathrm{MgO}+\mathrm{CO}_{2}-\mathrm{Q}_{1}$ and $\mathrm{CaCO}_{3} \rightarrow \mathrm{CaO}+\mathrm{CO}_{2}-\mathrm{Q}_{2}$, which require substantial consumption of thermal energy, should be considered as thermally activated decarbonization processes having practical importance in metallurgy. It should be mentioned that $\mathrm{Q}_{1}=1,21 \cdot 10^{5} \mathrm{~J} / \mathrm{mol}$ is thermal effect of $\mathrm{MgCO}_{3}$ decomposition reaction, while

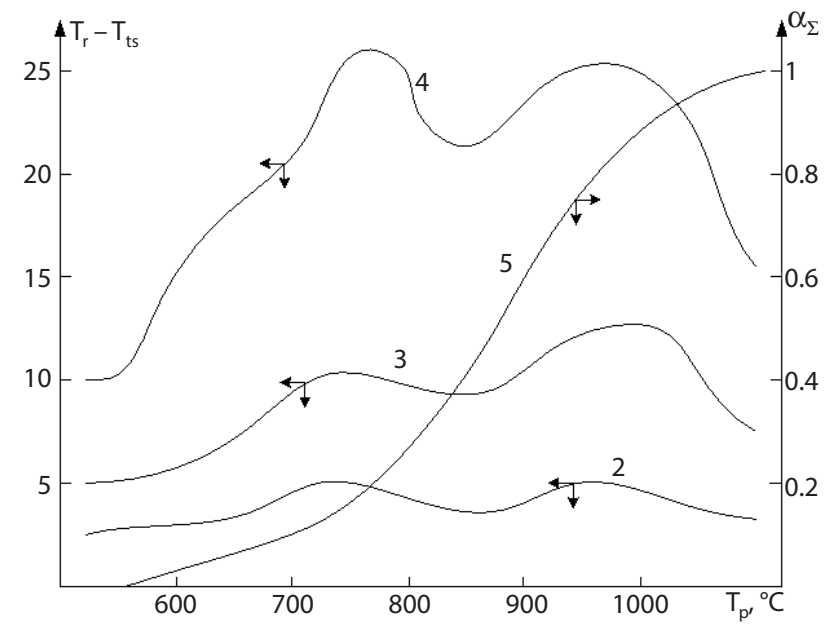

Fig. 2. Temperature gradients in the spherical iron ore pellet: heating rate $b=0.14 K \cdot \mathrm{s}^{-1}, 2-4-$ measurement data of thermometers, 5 - transformation degree

$\mathrm{Q}_{2}=1,78 \cdot 10^{5} \mathrm{~J} / \mathrm{mol}$ is thermal effect of $\mathrm{CaCO}_{3}$ decomposition reaction.

Conduction of kinetic analysis of topochemical reactions is usually accompanied by use of reaction variable $\alpha$ presenting the relation: $\alpha=\left(G_{0}-G(\tau)\right) / G_{0}=1-G(\tau) / G_{0}$, where $G_{0}$ is amount of reacting substance and $G(\tau)$ is amount of reacted substance during $\tau$ time.

The fields of temperature gradients in the examined samples are provided by action of non-stationary heating conditions and appearances of thermal effects of chemical transformations; they can be determined from the heat conductivity equation solutions with heat sinks and corresponding boundary conditions [16, 17].

Taking into account the main requirements and admissions, the mathematical formulation of the task in one-dimensional setting for a pellet looks like:

$$
\left\{\begin{array}{l}
\rho C_{P}\left(T, \alpha_{1}, \alpha_{2}\right) \frac{\partial T}{\partial \tau}=\frac{1}{x^{2}} \frac{\partial}{\partial x}\left(\lambda\left(T, \alpha_{1}, \alpha_{2}\right) x^{2} \frac{\partial T}{\partial x}\right)- \\
\quad-C_{1}^{0} Q_{1}^{0} \frac{\partial \alpha_{1}}{\partial \tau}-C_{2}^{0} Q_{2}^{0} \frac{\partial \alpha_{1}}{\partial \tau} ; \\
\frac{\partial \alpha_{1}}{\partial \tau}=k_{01} \exp \left(-\frac{E_{1}}{R_{0} T}\right)\left(1-\alpha_{1}\right)^{2 / 3} ; \\
\frac{\partial \alpha_{2}}{\partial \tau}=k_{02} \exp \left(-\frac{E_{2}}{R_{0} T}\right)\left(1-\alpha_{2}\right)^{2 / 3} .
\end{array}\right.
$$

Where $C_{1,2}^{0}$ are heat capacity values of the substances of reacted carbonates; $E_{1,2}$ are values of energy activation of carbonates dissociation; $k_{01,02}$ are pre-exponential multipliers; $\alpha_{1}$ is $\mathrm{MgCO}_{3}$ transformation degree; $\alpha_{2}$ is $\mathrm{CaCO}_{3}$ transformation degree; $\rho C_{P}\left(T, \alpha_{1}, \alpha_{2}\right), \lambda\left(T, \alpha_{1}, \alpha_{2}\right)$, are TPPs, specific heat capacity and heat conductivity, depending on temperature and transformation degrees of carbonates dissociation reactions. In particular, their temperature relationships are given on the Fig. 1. 


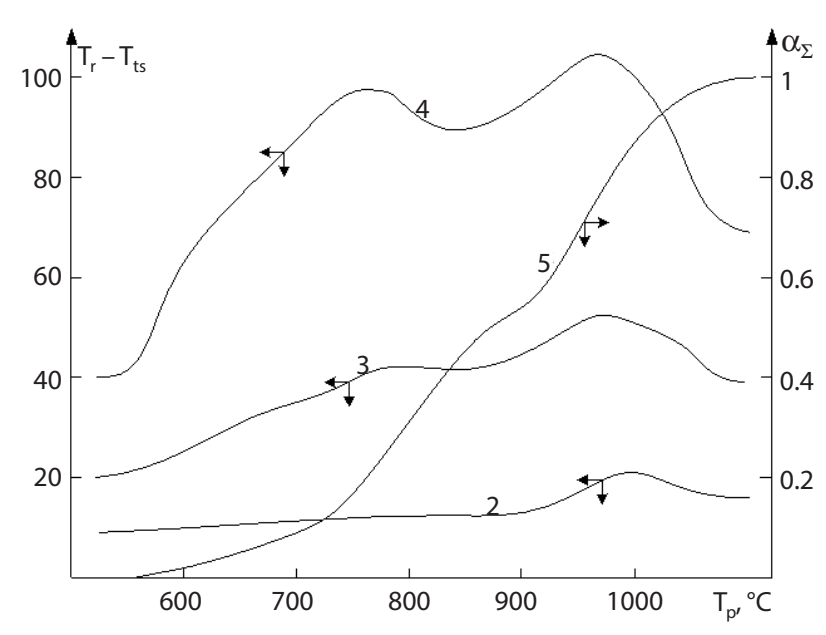

Fig. 3. Temperature gradients in the spherical iron ore pellet: heating rate $b=0.42 \mathrm{~K} \cdot \mathrm{s}^{-1}, 2-4-$ measurement data of thermometers, 5 - transformation degree

The system of equations was solved numerically with the following boundary conditions - with initial conditions:

$$
T(x, 0)=T_{0}, \quad \alpha_{1}(x, 0)=0, \quad \alpha_{2}(x, 0)=0
$$

And boundary conditions of the second and first order

$$
\frac{\partial T(0, \tau)}{\partial x}=0 ; \quad T(R, \tau)=T_{P}(\tau)
$$

where $T(x, \tau)$ is the pellet temperature depending on the pellet radius coordinate $(x)$ and time $(\tau)$. Solution of the presented system of equations was realized via passing by subtended finite-difference scheme.

However, calculated determination of the values of temperature gradients can be executed rather approximately, due to absence of substantiated data on temperature and temporary TPP relationship for iron ore raw material as well as on kinetics of thermal decarbonization (which is determined by density among heat sink (from one side) and temperature, coordinate and time (from other side)) $[18,19]$.

\section{Planning of the experiment}

To determine the temperature gradients in the samples of calcinated iron ore raw material depending on the heating conditions and qualitative estimation of the procedure of heterogeneous decomposition reaction of carbonate inclusions, calcination of a spherical sample (a pellet) with 0.015 $m$ radius was conducted in the thermal gravimetric unit with simultaneous registration of weight loss and temperature distribution in the samples.

Calcination was conducted with linear temperature increase on the sample surface, with rates $b_{1}=0.14 K \cdot \mathrm{s}^{-1}$, $b_{2}=0.42 \cdot s^{-1}$. The results of experiments are presented on the Fig. 2 and Fig. 3.

Temperature gradients in the volume of spherical pellet $T_{\mathrm{r}}-T_{\mathrm{ts}}$ were measured by four differential thermoelectric

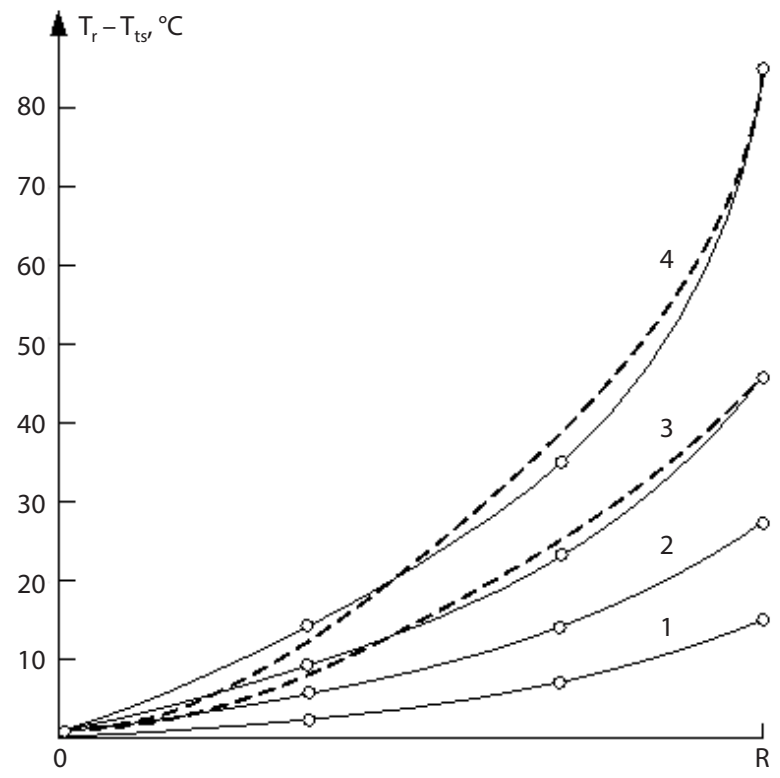

Fig. 4. Temperature distribution in a spherical iron ore pellet from the beginning of the reaction (curves 1,3 at $T_{\mathrm{ts}}=550{ }^{\circ} \mathrm{C}$ ) and during the reaction (curves 2, 4 at $T_{\mathrm{ts}}=750{ }^{\circ} \mathrm{C}$ ): surface heating rates are: $b=0.14 K \cdot \mathbf{s}^{-1}($ curves 1,2$)$, $b=0.42 K \cdot \mathrm{s}^{-1}($ curves 3,4$)$

thermometers (in the center $T_{1}=T_{t s}$, when $r=1-$ line 1 (coincides with the horizontal axis), at the distance $5 \mathrm{~mm}$ from the center $T_{2}-$ line 2 , at the distance $10 \mathrm{~mm}$ from the center $T_{3}-$ line 3 , on the pellet surface $T_{4}=T_{p}-$ line 4 ) and were related to the surface temperature. Weight loss of the samples was presented in the following coordinates: pellet surface temperature - total transformation degree $\alpha_{\Sigma}$ (average by coordinate), which was determined via the relationship: $\alpha_{\Sigma}=\left(G_{r}-G\left(T_{P}\right)\right) /\left(G_{r}-G_{a n}\right)$, where $G_{r}$, $G_{a n}$ - sample weights in raw and completely annealed state respectively; $G\left(T_{P}\right)$ - current sample weight, normalized to the surface temperature.

Temperature distribution along pellet radius, corresponding to the moments (a) before carbonates dissociation reaction (quasi-stationary heating procedure) and (b) during intensive conduction of decarbonization process, is presented on the Fig. 4.

Let's compare the experimental temperature distributions with theoretical ones (see dotted line on the Fig. 4); they have parabolic shape, in correspondence with the known solution of the sphere heat conductivity equation for quasi-stationary heating procedure.

\section{Analysis and discussion of results}

Comparison of the temperature distributions displays that this distribution is close to parabolic one from the moment of starting of the quasi-stationary heating procedure and until beginning of the carbonates dissociation reaction in a pellet. At the same time temperature gradient increases slightly with temperature rise [20-22], but it increases 
dramatically with a sample weight loss and is characterized by two maximal points. It should be noted as a feature that kind of temperature gradient has not essential distortions. The temperature gradients are higher after finishing of decarbonization reaction than in a "green" (non-roasted) sample.

The following conclusions and scientifically substantiated suggestions can be done based on the experimental results: - calcination of iron ore pellets with dimensions and heating rates close to those that take place in the acting roasting conveyor-type machines during roasting and realized during practical thermal analytical researches is conducted with essential temperature gradients;

- Decarbonization of iron ore raw material occurs mainly during two stages, when the process covers whole sample (or at least its substantially wide area); this conclusion is testified by absence of fracture along the temperature distribution curve, that is typical for phase transformations occurring on the surface or narrow area and accompanying by significant absorption of thermal energy;

- Heating of iron ore material and conducted physicalchemical transformation in this material are accompanied by essential variations of thermal physical parameters.

It is evident that varying of thermal physical properties in iron ore raw material for approved heating procedure leads to varying of conditions of internal heat exchange in the reacting sample and effects thereby on the dynamics of heterogeneous transformation.

The effect of heating rate on pellets surface on macro-kinetics of thermal decarbonization was revealed. The calculations conducted for the presented model with different heating rates show that increase of heating rate and corresponding increase of temperature gradients will finalize in rise of heterogeneity of concentrations of reacting carbonates. Forming of heterogeneous field of concentrations and appearance of temperature gradients in a pellet promote extremal distribution of carbonates dissociation heating rate, while its maximum is transferred deep in a pellet as soon as the reaction is conducting. It was found out that the maximal point crossing by the local reaction rates is the lower, the larger is the distance between the corresponding point and pellet surface. The values of the reaction rate maximum points increase with growth of the heating rate, what promotes rise of temperature gradients in a pellet.

\section{Conclusion}

Chemical-metallurgical calcination process of pelletized iron ore raw material was experimentally tested with use of samples saving their initial structure in the temperature range of high-temperature roasting in conveyor-type roasting machines. Wide variation of heating rates of iron ore pellets in a roasting machine conveyor was taken into account during experiments. Appearance of essential temperature gradients in the examined samples was revealed; it is connected with non-stationary heating conditions and thermal effects of carbonates dissociation reaction, which restricts in its turn possibility of use of the existing methods of non-isothermal kinetics for determination of kind and parameters of kinetic equations. The feedback among thermal physical calcination conditions and accompanying heterogeneous endothermic transformations was found out. Possibility of use of the existing methods for correct analysis of these chemical-metallurgical processes was determined.

Numerical investigations of the calcination process mathematical model testify on significant effect of internal heat exchange and parameters of the kinetic equation on conduction of carbonates dissociation reaction. The error values depend on parameters of the kinetic equations. Stability of the process parameters leads to increase of the error values in their determination based on the results of thermal analytical experiments. This increase is observed as a result of increase of heating rate of the samples, increase of their dimensions, increase of thermal effect of the reaction, increase of concentration of the reacting phase as well as of lowering of temperature conductivity of the samples. I. e. increase of the factors elevating steepness of the temperature gradient field in pellets.

Calcination process of iron ore raw material can be calculated using the presented model in a wide range of heating rates of pellets on fire grate for the existing roasting conveyortype machines, what allows to determine the optimal conditions of calcination process.

The research was conducted under financial support of the Russian Foundation for Basic Research (RFFI) within the scientific project No. 18-29-24094 MK and the Government Order, the project No. FSWF-2020-0019.

\section{REFERENCES}

1. Bobkov V. I., Dli M. I., Sokolov A. M., Rubin Y. B. Analysis of chemical-metallurgical agglomeration processes during charge sintering. CIS Iron and Steel Review. 2020. Vol. 20. pp. 7-11.

2. Guro V. P., Yusupov F. M., Safarov E. T., Rakhmatkarieva F. G. Thde choice of optimal binder for molybdenate concentrate granulation. Tsvetnye metally. 2016. No. 2. pp. 68-73.

3. Nayak D., Ray N., Dash N., Pati S., De P. S. Induration aspects of low-grade ilmenite pellets: Optimization of oxidation parameters and characterization for direct reduction application. Powder Technology. 2021. Vol. 380. pp. 408-420.

4. Meshalkin V. P., Bobkov V. I., Dli M. I., Fedulov A. S. Mathematical simulation of chemical and energotechnological processes and procedures of coke fines burning in agglomerated layer. CIS Iron and Steel Review. 2020. Vol. 19. pp. 13-17.

5. Wang S., Guo Y., Zheng F., Chen F., Yang L. Improvement of roasting and metallurgical properties of fluorine-bearing iron concentrate pellets. Powder Technology. 2020. Vol. 376. pp. 126-135.

6. Bokovikov B. A., Bragin V. V., Shvydkii V. S. Role of the thermalinertia zone in conveyer roasting machines. Steel in Translation. 2014. Vol. 44. No. 8. pp. 595-601.

7. Li J., An H.-F., Liu W.-X., Yang A.-M., Chu M.-S. Effect of basicity on metallurgical properties of magnesium fluxed pellets. Journal of Iron and Steel Research International. 2020. Vol. 27. No. 3. pp. 239-247.

8. Tian H., Pan J., Zhu D., Wang D., Xue Y. Utilization of Ground Sinter Feed for Oxidized Pellet Production and Its Effect on Pellet Consolidation and Metallurgical Properties. Minerals, Metals and Materials Series. 11th International Symposium on High-Temperature Metallurgical Processing. 2020. pp. 857-866.

9. Matkarimov S. T., Berdiyarov B. T., Yusupkhodjayev A. A. Technological parameters of the process of producing metallized iron concentrates from poor raw material. International Journal of Innovative Technology and Exploring Engineering. 2019. Vol. 8. No. 11. pp. 600-603. 
10. Bragin V. V., Bokovikov B. A., Naidich M. I., Gruzdev A. I., Shvydkii V. S. Relation between the productivity and fuel consumption in roasting machines. Steel in Translation. 2014. Vol. 44. No. 8. pp. 590-594.

11. Akberdin A. A., Kim A. S., Sultangaziev R. B. Experiment Planning in the Simulation of Industrial Processes. Steel in Translation. 2018. Vol. 48. No. 9. pp. 573-577.

12. Shyydkii V. S., Fatkhutdinov A. R., Devyatykh E. A., Devyatykh T. O., Spirin N. A. On mathematical modeling of layer metallurgical furnaces and aggregates. Report 2. Izvestiya vuzov. Chernaya metallurgiya. 2017. Vol. 60. No. 1. pp. 19-23.

13. Yuryev B. P., Goltsev V. A. Change of equivalent layer porosity of pellets along the length of burning conveyor machine. Izvestiya vuzov. Chernaya metallurgiya. 2017. Vol. 60. No. 2. pp. 116-123.

14. Shvydkii V. S., Yaroshenko Y. G., Spirin N. A., Lavrov V. V. Modeling of metalized pellets firing with the account of physicochemical transformations in them. Izvestiya vuzov. Chernaya metallurgiya. 2018. Vol. 61. No. 4. pp. 288-293.

15. Novichikhin A. V., Shorokhova A. V. Procedures for stage processing of iron-ore wastes in industrial mining areas. Izvestiya vuzov. Chernaya metallurgiya. 2017. Vol. 60. No. 7. pp. 565-572.

16. Bobkov V. I., Borisov V. V, Dli M. I., Meshalkin V. P. Multicriterial optimization of the energy efficiency of the thermal preparation of raw materials. Theoretical Foundations of Chemical Engineering. 2015. Vol. 49. No. 6. pp. 842-846.
17. Bobkov V. I., Borisov V. V., Dli M. I., Meshalkin V. P. Intensive Technologies for Drying a Lump Material in a Dense Bed. Theoretical Foundations of Chemical Engineering. 2017. Vol. 51. No. 1. pp. 70-75.

18. Tian Y., Qin G., Zhang Y., Zhao L., Yang T. Experimental research on pellet production with boron-containing concentrate, Chara-cterization of Minerals, Metals, and Materials. Minerals, Metals and Materials Series 2020. pp. 91-102. DOI: 10.1007/9783-030-36628-5_9.

19. Yaroshenko Y. G. Thermal physics as the basis for energy and resource conservation in steelmaking. Steel in Translation. 2017. Vol. 47. No. 8. pp. 505-516.

20. Yang C.-C., Zhu D.-Q., Pan, J., Zhou B.-Z., Xun H. Oxidation and Induration Characteristics of Pellets Made from Western Australian Ultrafine Magnetite Concentrates and Its Utilization Strategy. Journal of Iron and Steel Research International. 2017. Vol. 23. No. 9. pp. 924-932.

21. Zhuravlev F. M., Lyalyuk V. P., Tarakanov A. K., Chuprinov E. V., Kassim D. A. Metallurgical characteristics of unfluxed pellets produced from concentrates with different mineral content. Steel in Translation. 2016. Vol. 46. No. 6. pp. 419-427.

22. Wang L., Liu W., Hu J., Xie H., Li C. Indirect mineral carbonation of titanium-bearing blast furnace slag coupled with recovery of $\mathrm{TiO}_{2}$ and $\mathrm{Al}_{2} \mathrm{O}_{3}$. Chinese Journal of Chemical Engineering. 2018. Vol. 26. No. 3. pp. 583-592. 